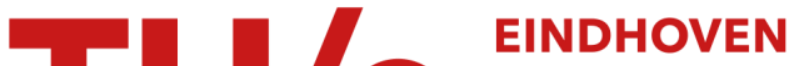 UNIVERSITY OF TECHNOLOGY
}

\section{On-body sensing: from gesture-based input to activity-driven interaction}

\section{Citation for published version (APA):}

Lukowicz, P., Amft, O. D., Roggen, D., \& Cheng, J. (2010). On-body sensing: from gesture-based input to activity-driven interaction. Computer, 43(10), 92-96. https://doi.org/10.1109/MC.2010.294

DOI:

10.1109/MC.2010.294

Document status and date:

Published: 01/01/2010

\section{Document Version:}

Publisher's PDF, also known as Version of Record (includes final page, issue and volume numbers)

\section{Please check the document version of this publication:}

- A submitted manuscript is the version of the article upon submission and before peer-review. There can be important differences between the submitted version and the official published version of record. People interested in the research are advised to contact the author for the final version of the publication, or visit the $\mathrm{DOI}$ to the publisher's website.

- The final author version and the galley proof are versions of the publication after peer review.

- The final published version features the final layout of the paper including the volume, issue and page numbers.

Link to publication

\section{General rights}

Copyright and moral rights for the publications made accessible in the public portal are retained by the authors and/or other copyright owners and it is a condition of accessing publications that users recognise and abide by the legal requirements associated with these rights.

- Users may download and print one copy of any publication from the public portal for the purpose of private study or research.

- You may not further distribute the material or use it for any profit-making activity or commercial gain

- You may freely distribute the URL identifying the publication in the public portal.

If the publication is distributed under the terms of Article 25fa of the Dutch Copyright Act, indicated by the "Taverne" license above, please follow below link for the End User Agreement:

www.tue.nl/taverne

Take down policy

If you believe that this document breaches copyright please contact us at:

openaccess@tue.nl

providing details and we will investigate your claim. 


\title{
On-Body Sensing: From Gesture-Based Input to Activity-Driven Interaction
}

\author{
$\rightarrow$ Paul Lukowicz, University of Passau \\ $\rightarrow$ Oliver Amft, TU Eindhoven and ETH Zurich \\ $\rightarrow$ Daniel Roggen, ETH Zurich \\ $\rightarrow$ Jingyuan Cheng, University of Passau
}

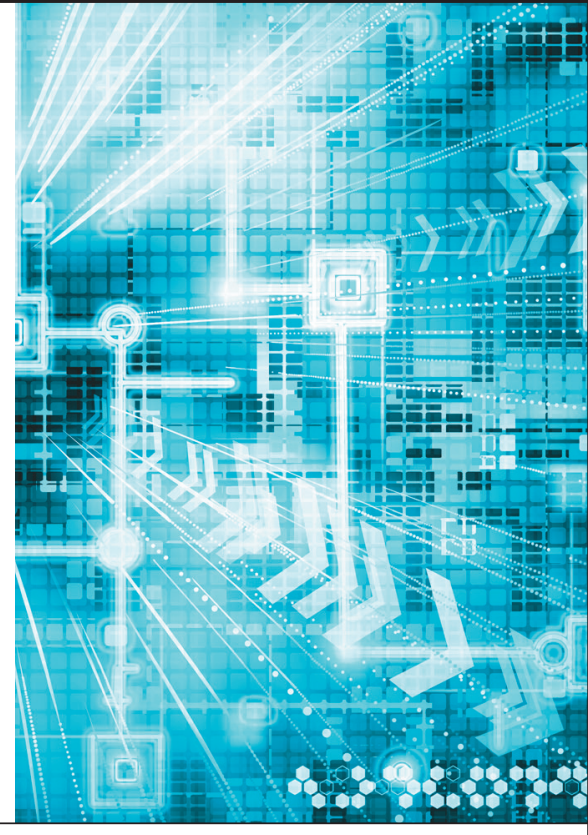

\section{Unobtrusive body-worn sensors can continuously interpret user activity and react proactively in sports, personal health, and many other application areas.}

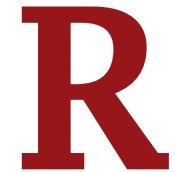
ecently, systems have emerged that utilize a broad range of sensors to facilitate gesture and motion-based interaction. Examples range from multitouch surfaces to tilt control to complex, motion-based game controllers. As these technologies become mainstream, research is already focusing on the next step: activity-driven, implicit interaction. Next-generation on-body sensing systems interpret complex human movements, rather than only gestures, and extend interaction from intermittent, conscious control to the permanent, automatic monitoring of user activities.

Conceptually, activity-driven interaction builds on the vision of context awareness. From a technology viewpoint, the key enabler is unobtrusive on-body sensing that seamlessly integrates with natural daily life. On-body sensing modalities can be divided into three categories: motion sensors that track a user's body motions, position, and orientation; wearable sensors that provide data about inner-body physiological processes ranging from muscle actions to cardiovascular activity to chewing and swallowing; and sensors that provide information about the user's environment.

\section{FROM WIIMOTE TO IPHONE 4 AND BEYOND}

The most common on-body motion sensors are accelerometers, which are used in commercial products such as step counters, mobile phones and cameras (to adjust screen orientation when the device is rotated), and game controllers such as the Wii Remote or "Wiimote" and the Xbox Kinect. Body-worn accelerometers can monitor a wide range of activities including modes of locomotion, daily movements, and production or maintenance processes.

At the signal level, accelerometers provide data about orientation with respect to the gravity vector (static acceleration) and change of speed (dynamic acceleration). For more advanced applications, they are often combined with gyroscopes and magnetic field sensors in an inertial measurement unit. An IMU provides data about orientation with respect to the coordinate system given by the gravity vector and the geographic north direction.

Using IMUs on each limb, it is possible to reconstruct exact motion trajectories of body parts. Because body motions determine most human activities, IMUs enable the recognition of complex movements as well as biomechanical applications such as rehabilitation or personal training. Initial commercial devices were relatively bulky, but researchers have integrated highly miniaturized, custom platforms in everyday-outfit prototypes. In addition, the incorporation of IMUs in the popular iPhone 4 should greatly broaden the application field.

As an alternative to IMUs, we have adapted magnetic resonant coupling to wearable sensing (G. Pirkl et al., "Adapting Magnetic Resonant Coupling Based Relative Positioning Technology for Wearable Activity Recognition," Proc. 2008 12th IEEE 

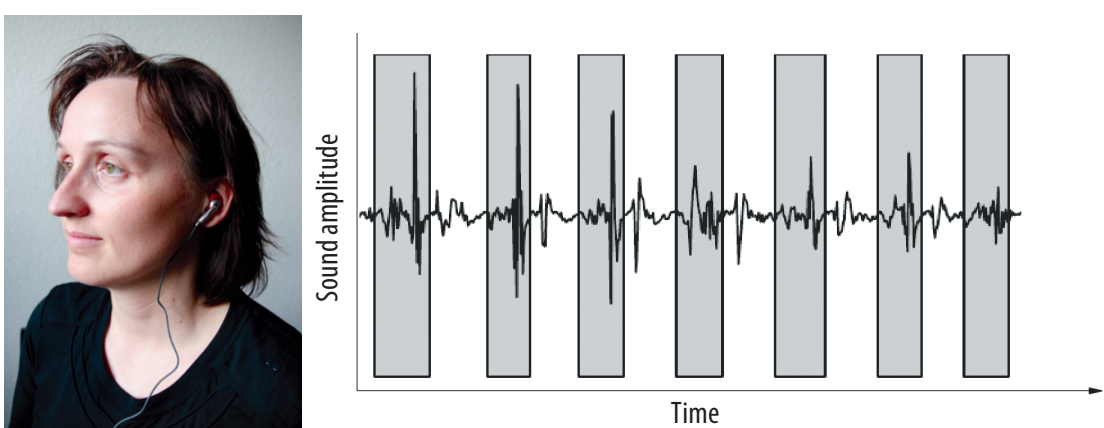

Figure 2. Sound signal related to chewing as recorded from an ear microphone.

It's possible to implement active capacitive sensing with textile electrodes that require no special attachment or body contact-it's even possible to attach the electrodes to the outer surface of a loose jacket. At the same time, the sensors can gather data on a broad range of activities from a single location on the body. For example, sensors mounted on the neck, back, and leg (Figure 1a) can recognize chewing, swallowing, head motions, and head positions (Figure 1b). In addition, pulse and breathing frequency are present in signals from most body locations.

The main challenge of active capacitive sensing is high sensitivity to noise and motion artifacts. Dealing with this problem is a focus of current research.

Another way to look inside the body is to rely on sound. Just as a physician uses a stethoscope to assess heart and lung functionality, we have used body sounds for dietary analysis. Chewing generates brief vibrations each time the teeth come together; these cyclic vibrations propagate through the mandible and skull. As Figure 2 shows, a device similar to a hearing-aid implant or portable headphones can sense chewing in sound and skin vibrations recorded at the ear canal. Because food has different material properties and textures that result in different vibration waveforms, the sensor can use chewing sounds to distinguish food categories.

\section{Sensing the World}

For implicit activity-driven interaction, a user's surroundings can be as important as his actions. In addition, user actions are often related to events in the environment-for example, when operating home appliances. What data can on-body sensors provide about the environment?

Sensors for parameters such as temperature, air pressure, and humidity are commonly found in watches, phones, and other consumer appliances. For recognizing more complex events, sound is the most versatile modality. Specific sounds are associated with certain environments (for example, a busy street versus background chatter at a cocktail party) and objects (for example, a door being open or closed or the whirring of a blender). We have demonstrated that embedded devices with limited computational power can reliably recognize such sounds. We have also shown that microphones integrated in mobile phones can be used for sound recognition, including methods to deal with damping caused by the clothing or bags in which the device is carried.

Researchers have also devoted considerable attention to body-worn cameras. However, problems associated with dynamic environments, computation complexity, and privacy concerns have thus far limited their applicability.

While not strictly sensors, Wi-Fi and Bluetooth devices can also be useful sources of information about the environment. The former can help identify specific locations, while the latter can identify people in the user's proximity. On a more abstract level, the number of Bluetooth devices, which many people keep permanently activated, can indicate crowd density.

\section{Application Domains}

On-body sensing has the potential to make information about users' activities, state, and environment available to applications at any time or place. This is already occurring in conjunction with sensor-rich mobile phones. Thus, for example, jogging applications monitor distance, number of steps, average speed, elevation difference, pulse, and so on. Users can review this data on their PC and upload it to a website for comparison with others' data.

Gaming and sports applications that are implicitly driven by realworld actions rather than by explicit commands directed at the system are also emerging. More complex scenarios that research groups have investigated include analysis of martial-arts movements, skiing, snowboarding, and even swimming.

Unobtrusive on-body sensing has attracted the interest of professional athletes. For example, miniature inertial sensors can help link ski jumpers' performance, expressed as jump distance, to coordinated motion activity. Acceleration sensors attached to the limbs and chest of Swiss ski jumper Simon Amman at the 2010 Olympics confirmed that initial lift acceleration at the moment of take-off was the key to his gold-medal victory (M. Bächlin et. al, "Ski Jump Analysis of an Olympic Champion with Wearable Acceleration Sensors," to appear in Proc. 2010 14th IEEE Int'l Symp. Wearable Computers, IEEE Press, 2010).

Closely related are personal health applications. The simplest involve logging a user's movement throughout the day to encourage a healthier life- 


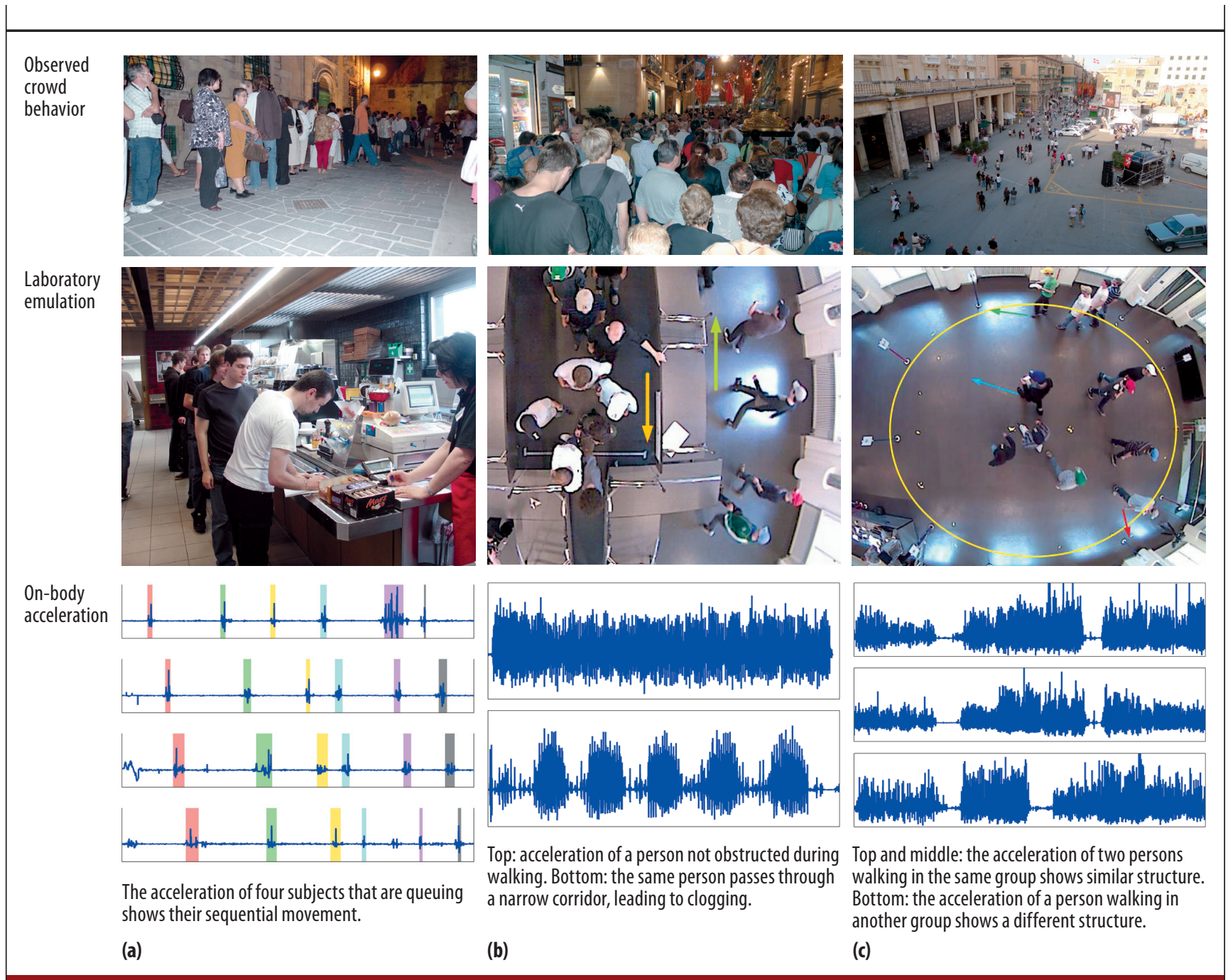

Figure 3. The SOCIONICAL system recognizes typical crowd behaviors by correlating signals from accelerometers carried by different individuals. (a) Queuing. (b) Clogging. (c) Group formations.

style, but often this includes online competition between users as a form of activity-driven game. Other applications can monitor and possibly coach food selection and consumption, enhancing or replacing unreliable handwritten diaries $(\mathrm{O}$. Amft and G. Tröster, "On-Body Sensing Solutions for Automatic Dietary Monitoring," IEEE Pervasive Computing, Apr. 2009, pp. 62-70).

Behavioral and cognitive disorders including dementia, autism, and Parkinson's disease are also a promising application field for body sensing and activity recognition. For example, MONARCA (www.monarca-project. eu) is a smartphone-based support system for the diagnosis and treat- ment of manic-depressive disorders The system will monitor everyday behavior patterns and map them onto risk factors, make recommendations, mediate interaction with doctors, and help assess therapeutic success.

Promising use cases for implicit activity-driven interaction also exist in production, maintenance, and process support. We recently evaluated the effect of using activity recognition to automatically deliver required maintenance information to a headmounted display and detect errors such as omitted or falsely executed procedure steps. The study, involving technicians and a real-world industrial task, revealed a 50 percent time savings over conventional paper documentation and a 30 percent advantage over a voice-recognitiondriven head-mounted display system.

\section{Sensing Collective Behavior}

With the smartphone market share approaching 30 percent and the increasing mass production of other sensor-equipped devices, it is safe to assume that activity-aware, interconnected systems will be widespread in public spaces in the near future. This will facilitate the evolution of sensing from individual activities to collective behavior.

As Figure 3 shows, the SOCIONICAL project (www.socionical.eu) uses sensor-enabled mobile phones to conduct real-time analysis of 
crowd behavior, which authorities can use to detect critical situations during public gatherings and to provide situational awareness to first responders during emergencies and disasters (M. Wirz, D. Roggen, and G. Troster, "Decentralized Detection of Group Formations from Wearable Acceleration Sensors," Proc. 2009 Int'l Conf. Computational Science and Eng., vol. 4, IEEE CS Press, pp. 952-959). It will also enable "emergency assistance" mobile phone applications that can provide individual guidance in such situations. Organizers could deploy system software as part of a downloadable event guide for rallies, concerts, or sports events, where its benefits potentially outweigh privacy concerns. Our studies suggest that the population is receptive to such applications.

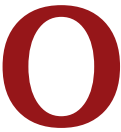
n-body sensing technology has recently progressed along two lines. First, sensors are increasingly being integrated into consumer devices such as mobile phones. Second, novel sensing concepts allow acquiring sophisticated information, including data about inner-body functionality, in an unobtrusive way. Together, these developments facilitate a new generation of interactive applications that replace explicit input, proactively reacting to users' actions in areas such as sports, healthcare, and industrial processes.

Several research obstacles remain. Novel sensing modalities must be integrated into mobile devices and clothing in such a way that they are commercially viable while retaining good signal quality. In addition, sensor data must be reliably mapped onto high-level activities, which involves devising new methods to deal with the variability of human actions, sensor ambiguities, and various noise sources. Finally, researchers must develop appropriate application and user models to ensure consumer acceptance and enhance the user experience. In particular, they must address fears about privacy intrusion and the loss of control of data, and they must determine how to handle recognition errors. [
Paul Lukowicz is a professor and heads the Embedded Systems Lab at the University of Passau, Germany. Contacthim at paul.lukowicz@ uni-passau.de.

Oliver Amft is an assistant professor at TU Eindhoven, the Netherlands, and a senior research advisor in the Wearable Computing Lab at ETH Zurich, Switzerland. Contact him at amft@ ieee.org.

Daniel Roggen is a senior research fellow in the Wearable Computing Lab at ETH Zurich. Contact him at daniel. roggen@ife.ee.ethz.ch.

Jingyuan Cheng is a postdoctoral researcher in the Embedded Systems Lab at the University of Passau. Contact her at jingyuan.cheng@ uni-passau.de.

Editor: Albrecht Schmidt, Institute for Computer Science and Business Information Systems, University of Duisburg-Essen, Germany; albrecht@computer.org

Selected CS articles and columns CD are available for free at http://ComputingNow.computer.org.

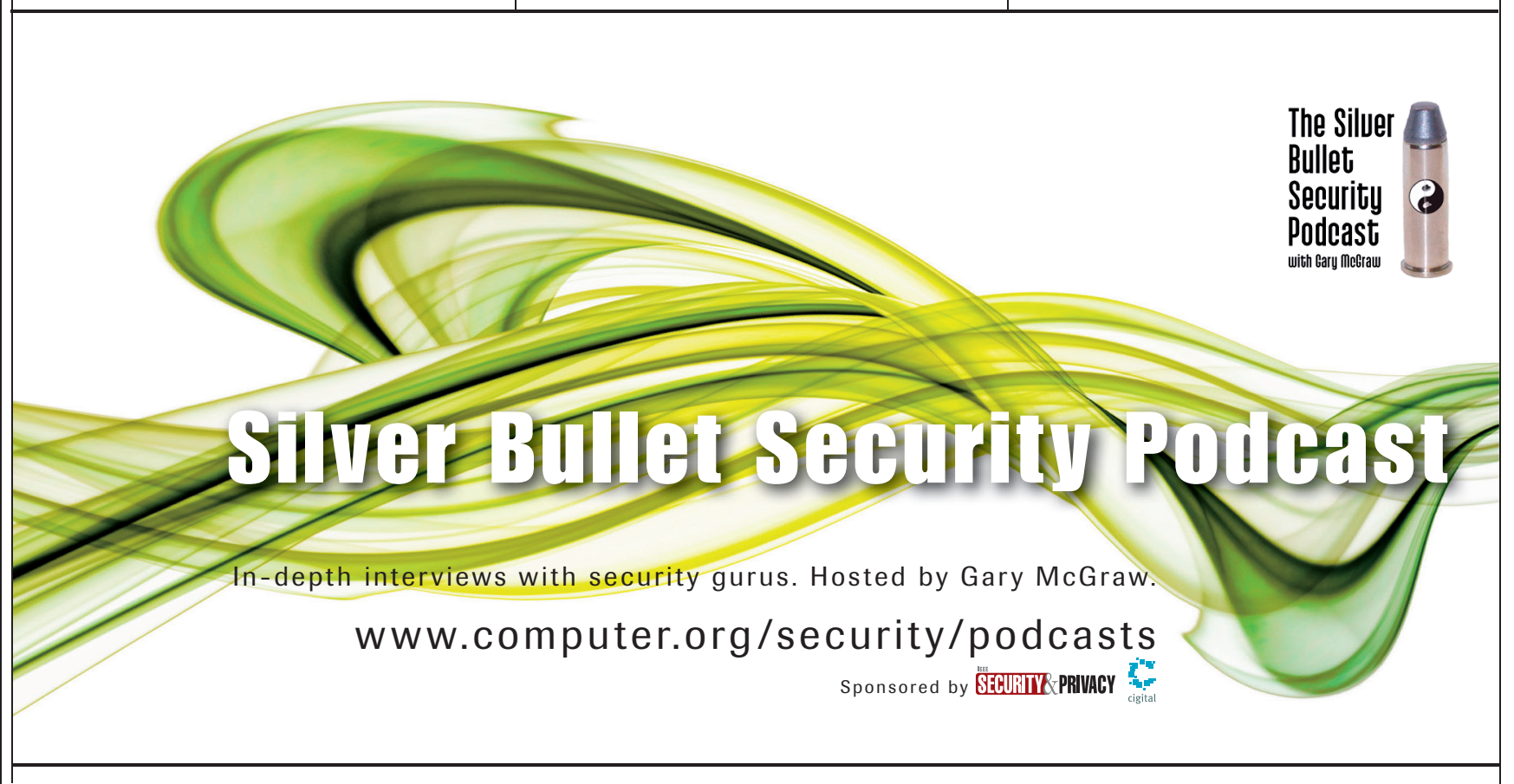

